\title{
Três versões de um mesmo Púchkin
}

LINO MACHADO

LINO MACHADO é mestre em Literatura Portuguesa pela Faculdade de Letras da UFRJ, onde

defendeu a dissertação Teatro $e$ Fiç̧ão em Mário de Sá-Carneiro. Teve textos criticos publicados na revista portuguesa Colóquio/Letras e, atualmente, participa do conselho editoral da revista 34 Letras.
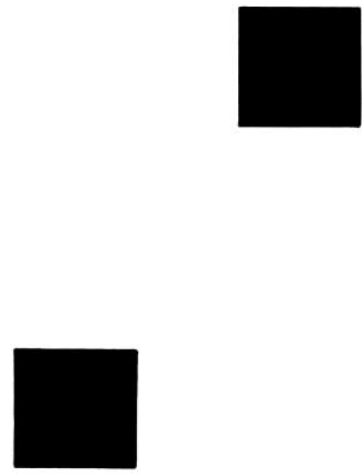

1 "Hybris da traduçăo, hybris da análise", in Coloquiohetras n 57. Lisboa, setembro de 1980, pp. 5-12.

\section{Ningún problema tan consustancial con las letras y con su} modesto misterio como el que propone una traducción.

(Borges, Discusión)

O número 57 da revista portuguesa Colóquio/Letras traz um interessante artigo de Boris Schnaiderman, dedicado à discussão de um poema de A. S. Púchkin ${ }^{(1)}$. Nele, o crítico apresenta o poema em alfabeto cirílico e uma transliteração do mesmo para a nossa grafia, acompanhados por uma versão literal em prosa e mais duas traduçōes em verso (uma da sua autoria e outra feita por Haroldo de Campos) do texto de Púchkin.

A transliteração do poema e a versão literal em prosa são as seguintes:

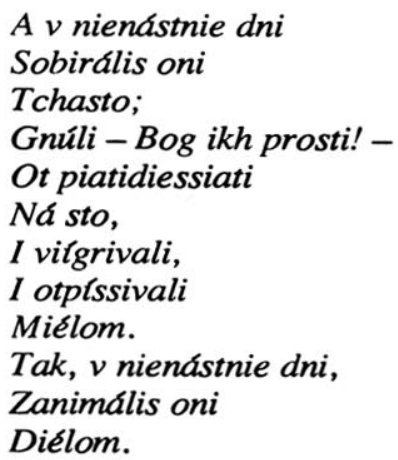

"Mas, nos dias de mau tempo, eles se reuniam com freqüência; dobravam - que Deus os perdoe! - de cinqüenta a cem, e ganhavam, e marcavam as apostas a giz. Assim, em dias de mau tempo, eles se ocupavam de coisa séria."

Mesmo o leitor que nada saiba de russo poderá, se quiser comparar o poema com a tradução dele em prosa, perceber a grande economia lingüística do original, bem como a sua ágil distribuição de rimas, a dosagem entre os versos mais longos e os mais curtos, a repetição intencional de cer'as palavras, etc.

Do poema em causa também tez Boris Schnaiderman uma tradução em versos, que agora cito:

"Nos dias de borrasca, Juntavam-se na tasca Com freqüência;

Dobravam - oh, Deus lhes perdoe bem! -

Com tamanha eficiência,

De cinqüenta a cem, 


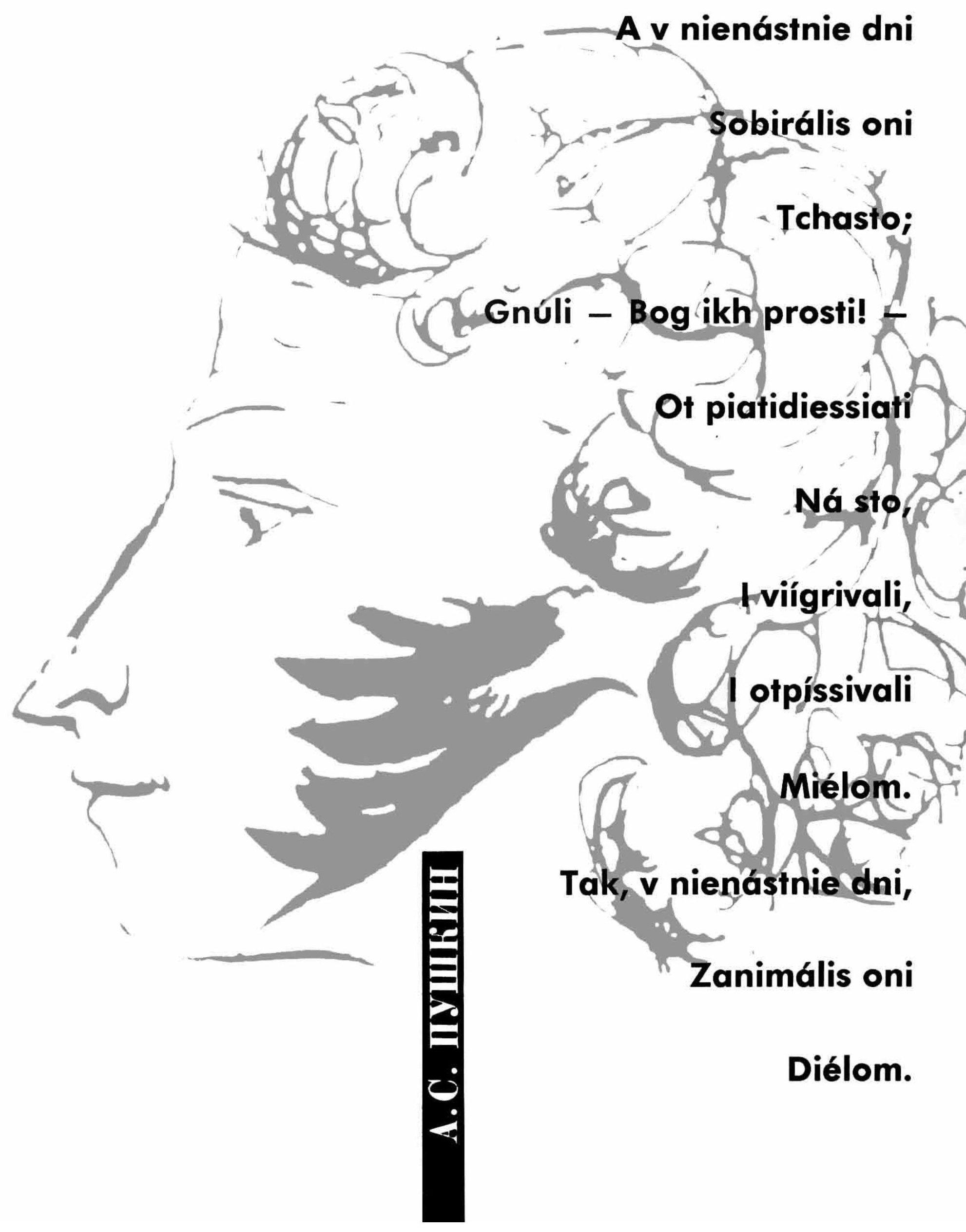



foi possível verter de alguma outra passagem.

Mas a nova recriação de Púchkin em nossa língua talvez não se apresente isenta de problemas, por admirável que seja. O uso do incomum verbo "trucar", junto com a elipse de "cem mais cem"'(3), pode tornar o texto obscuro para muitos leitores. E não me parece que a ironia de Púchkin no final do poema fique suficientemente clara em "Encargos graves/na tasca", que busca fazer eco à atividade "séria" a que se entregam os jogadores do poeta russo. Descontadas tais observações, contemos com mais uma interessante peça de tradução a ser acrescentada às muitas com que Haroldo de Campos vem ampliando as possibilidades literárias da língua portuguesa.

Como ele, também fui motivado pelo artigo de Boris Schnaiderman, a ponto de igualmente tentar verter o curto texto do famoso poeta do Ievguêni Oniéguin. O que resultou no seguinte:

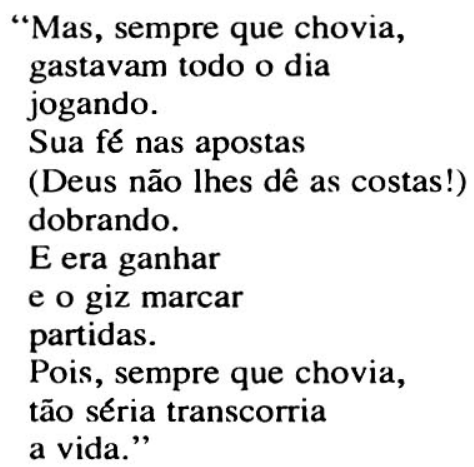

Mantive o esquema rímico do texto de origem. Esforcei-me também por preservar uma regularidade métrica que refletisse algo da que foi estabelecida por Púchkin. Minha versão, qualquer que seja a validade que tenha, resultou mesmo de um longo esforço para não fugir das imposições de rimas e métrica que aceitei. Tais limitações formais condicionaram as soluções semânticas da tradução. Daí, em parte, o afastamento num ponto e noutro do texto em português, em relação ao significado literal da composição de Púchkin. Suponho que aquilo que acrescentei por minha conta não agride o original.

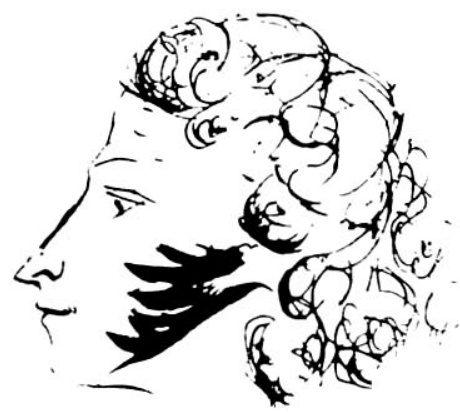

Assim, a idéia de os jogadores "gastarem" os seus dias nas cartas, com o possível trocadilho que o verso proporciona (gastar o tempo, gastar dinheiro), não chega a ser uma infidelidade à cena descrita pelo poeta. Do mesmo modo a aproximação entre a "fé nas apostas" e o "Deus" que não deve ser severo com os jogadores, se inexiste nos versos em russo, não destoa da visão irônica que o escritor reservou para o ambiente que apresenta.

Acredito também que a série de enjambements que constituem os versos mais curtos da composição aparece razoavelmente traduzida pela seqüência de “jogando”, “dobrando", "partidas" e "a vida".

Como foi dito anteriormente, mesmo quem não conheça o idioma do original pode captar algo de suas qualidades através da versão em prosa de Boris Schnaiderman. Encontrando-me na mesma situação de um tal leitor, nāo resisti à tentação de recriar o texto em português... fazendo do seu primeiro tradutor e analista um involuntário colaborador meu. Bom seria se uma quarta pessoa, dominando ou não a língua estrangeira, fosse levada a refazer a experiência estética que o condensado texto de Aleksandr Serguévitch Púchkin proporciona.

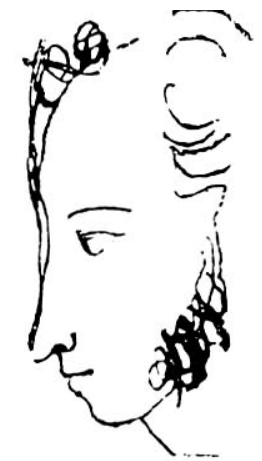

Nesta página, auto-retratos de Púchkin; na outra página, um retrato do poeta russo, por Kiprenski, 1827

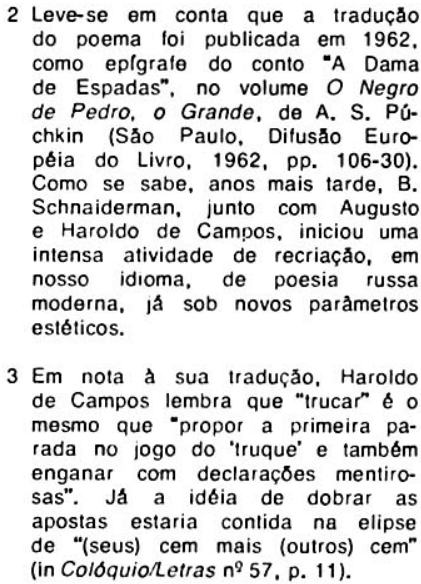
do poema foi publicada em 1962 como eplgrafe do conto "A Dama de Espadas", no volume O Negro de Pedro, o Grande, de A. S. Púchkin (Săo Paulo, Difusăo Européia do Livro, 1962, pp. 106-30) Como se sabe, anos mais tarde, Como se sabe, anos mais tarde, B. Schnaiderman, junto com Augusto e Haroldo de Campos, iniciou uma intensa atividade de recriaçăo, em nosso idioma, de poesia russa moderna, jấ sob novos parâmetros estéticos.

$3 \mathrm{Em}$ nota à sua tradução, Haroldo de Campos lembra que "trucar" é o mesmo que "propor a primeira parada no jogo do 'truque' e também enganar com declaraçठes mentiro sas". Já a idéia de dobrar as apostas estaria contida na elipse de "(seus) cem mais (outros) cem" (in Coloquio/Letras $n^{2} 57$, p. 11). 